\section{Pediatric \\ Neurosurgery}

\title{
International/Resident Traveling Fellowship Notice 2019
}

\section{Resident Traveling Fellowship in Pediatric Neurosurgery}

The Joint Pediatric Neurosurgery Section of the American Association of Neurological Surgeons and Congress of Neurological Surgeons offers a traveling fellowship for residents in accredited North American neurosurgical training programs. The fellowship is intended to cover the traveling and living expenses for 1 month for a resident who wishes to obtain additional experience in pediatric neurosurgery during residency.

The 1-month fellowship can be spent at any pediatric neurosurgery program within North America to pursue an activity which broadens the resident's exposure to pediatric neurosurgery, including observation at a clinical or research center, participation in a research project, or any other relevant activity.

Up to 4 fellowships per year are awarded on the basis of a competitive evaluation by a committee of the Joint Pediatric Section. The maximum fellowship stipend is USD 2,500.

The application must include:

1. a statement defining the purpose of the proposed fellowship;

2. written permission from the applicant's residency program director to pursue the 1-month fellowship if it is awarded;

3. a letter of acceptance from the pediatric neurosurgical program where the applicant will seek the fellowship;

4. the applicant's current curriculum vitae.

The strict deadline for application submission is November 6, 2020. The completed application should be e-mailed to:

ajea@iuhealth.org

Andrew Jea, MD, MHA, FACS, FAAP

Riley Hospital for Children

Department of Neurological Surgery

Indiana University School of Medicine

705 Riley Hospital Drive, Suite 1601, Indianapolis, IN 46202 (USA)

Tel. +1 3179446201

\section{International Traveling Fellowship in Pediatric Neurosurgery}

The Joint Pediatric Neurosurgery Section of the American Association of Neurological Surgeons and Congress of Neurological Surgeons offers an international traveling fellowship for neurosurgeons who, at the time of their application, are either training in a residency program outside the United States and Canada or who have completed residency training outside the United States and Canada within the past 5 years.

The fellowship will cover the traveling and living expenses for a 3-month period to be spent observing the activities of an established pediatric neurosurgical service of the applicant's choosing in the United States or Canada. Up to 2 fellowships will be awarded yearly on the basis of a competitive evaluation by a committee of the Pediatric Section at the annual meeting in December. The maximum fellowship stipend is USD 7,500.

The application must include:

1. a statement defining the purpose of the proposed fellowship;

2. a letter of recommendation from the applicant's current neurosurgical program director;

3. a letter of acceptance from the institution where the applicant intends to take the fellowship, confirming the description of the fellow's potential activities during the period of the award;

4. the applicant's current curriculum vitae.

The strict deadline for application submission is November 6, 2020. The completed application should be emailed to:

ajea@iuhealth.org

Andrew Jea, MD, MHA, FACS, FAAP

Riley Hospital for Children

Department of Neurological Surgery

Indiana University School of Medicine

705 Riley Hospital Drive, Suite 1601, Indianapolis, IN 46202 (USA)

Tel. +1 3179446201 